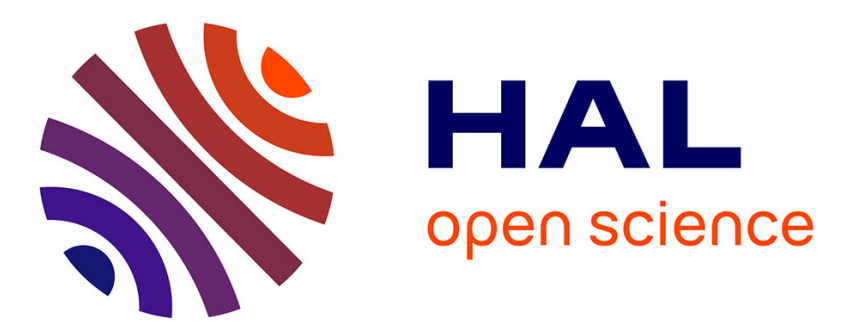

\title{
Analysis of hybrid fracture in $\alpha / \beta$ titanium alloy with lamellar microstructure
}

Ning Dang, Shuai Chen, Lingyu Liu, Eric Maire, Jérôme Adrien, Sophie Cazottes, Wenlong Xiao, Chaoli Ma, Lian Zhou

\section{- To cite this version:}

Ning Dang, Shuai Chen, Lingyu Liu, Eric Maire, Jérôme Adrien, et al.. Analysis of hybrid fracture in $\alpha / \beta$ titanium alloy with lamellar microstructure. Materials Science and Engineering: A, 2019, 744, pp.54-63. 10.1016/j.msea.2018.12.007 . hal-01985058

\section{HAL Id: hal-01985058 https://hal.science/hal-01985058}

Submitted on 17 Jan 2019

HAL is a multi-disciplinary open access archive for the deposit and dissemination of scientific research documents, whether they are published or not. The documents may come from teaching and research institutions in France or abroad, or from public or private research centers.
L'archive ouverte pluridisciplinaire HAL, est destinée au dépôt et à la diffusion de documents scientifiques de niveau recherche, publiés ou non, émanant des établissements d'enseignement et de recherche français ou étrangers, des laboratoires publics ou privés. 


\title{
Title: Analysis of hybrid fracture in $\alpha / \beta$ titanium alloy with
}

\section{lamellar microstructure}

Author: Ning $\mathrm{DANG}^{\mathrm{a}, \mathrm{b}}$, Shuai $\mathrm{CHEN}^{\mathrm{c}}$, Lingyu $\mathrm{LIU}^{\mathrm{d}}$, Eric MAIRE ${ }^{\mathrm{b}, *}$, Jérôme ADRIEN $^{\mathrm{b}}$, Sophie CAZOTTES ${ }^{\mathrm{b}}$, Wenlong XIAO ${ }^{\mathrm{a}, *}$, Chaoli MA $^{\mathrm{a}}$, Lian ZHOU ZHe $^{\mathrm{a}, \mathrm{e}}$

${ }^{a}$ Key Laboratory of Aerospace Advanced Materials and Performance of Ministry of Education,

School of Materials Science and Engineering, Beihang University, Beijing 100191, China

${ }^{\mathrm{b}}$ Université de Lyon, INSA de Lyon, MATEIS CNRS-UMR 5510, F-69621 Villeurbanne, France

${ }^{\mathrm{c}}$ Université de Lyon, INSA de Lyon, LAMCOS CNRS-UMR 5259, F-69621 Villeurbanne, France

${ }^{\mathrm{d}}$ Baoti Group Co., Ltd., Baoji, 721014, China

${ }^{\mathrm{e}}$ Northwest Institute for Nonferrous Metal Research, Xi'an 710016, China

\begin{abstract}
An integrated experimental-numerical method combining a realistic microstructure-based isotropic crystal-plasticity $(\mathrm{CP})$ model and fracture surface analysis was adapted to analyze the fracture behavior of the titanium alloy Ti-6Al-4V. A hybrid fracture mode consisting of cleavage facets and elongated dimples was observed and analyzed. With the help of numerical simulations and post-mortem SEM, the micro-mechanism of the hybrid fracture mode was revealed.
\end{abstract}

\footnotetext{
*Corresponding author.

E-mail: eric.maire@ insa-lyon.fr (Eric MAIRE);

wlxiao@buaa.edu.cn (Wenlong XIAO)
} 
The results show that ruptured $\alpha$ lamellae can be linked to cleavage facets induced by the development of voids. Simultaneously, hard $\beta$ lath can function as walls that separate two neighboring arrays of voids or micro-cracks within the $\alpha$ lamellae. The origin of this behavior can be associated with a heterogeneous stress/strain distribution in the $\alpha / \beta$ phases, which was revealed via numerical simulations. Further, the influence of the $\alpha$ grain orientation on the void evolution was investigated by varying the Schmid factor of the grains in simulations.

Keywords: Crystal plasticity; Spectral method; Fracture behavior; Titanium alloys; Deformation heterogeneities.

\section{Introduction}

Owing to their low density, high specific strength, and excellent corrosion resistance, two-phase $\alpha / \beta$ titanium alloys are widely used in modern industrial applications, such as airplane components, medical devices and implants[1-3]. At ambient temperature, these alloys consist predominantly of an HCP $\alpha$-phase and a BCC $\beta$-phase. The heterogeneous deformation behavior of the two phases leads to plastic incompatibilities[2,3] which promote a damage initiation in the form of void nucleation and growth. The $\alpha / \beta$ interface decohesion[4-7] occurs especially in alloys with long straight interfaces(full lamellar 
microstructure)[8,9]. To expand the future use of these alloys, it is necessary to understand well the relation between plastic inhomogeneity and damage initiation. Furthermore, because of the strong dependence of the plastic behavior on the microstructure, the microstructure morphology should be taken into consideration. As demonstrated by many investigations [10-17], realistic microstructure-based crystal plasticity $(\mathrm{CP})$ methods are suitable to investigate the role of the microstructure regarding plasticity deformation and damage evolution in metallic materials[18,19], since the local deformation behavior is predicted more accurately by these methods [20-28].

With further developing of computational capacity, plenty of image-based models for materials have been created for simulations and property evaluations [11,29-36]. In addition to finite element method(FEM), another robust spectral solver, based on fast Fourier transform(FFT) and Green's function method[33-38], was proposed[39-42]. It exhibits more advantages than FEM in dealing with representative volume elements(RVEs) subjected to periodic boundary conditions[43-45].

In this study, we analyzed the relation between microstructure inhomogeneity and fracture behavior with the help of an integrated experimental-simulation method. A realistic microstructure-based RVE was generated to model isotropic $\mathrm{CP}$ and tensile deformation simulation 
using a FFT method. Generally, for Ti alloys, most CP models only consider slip and twinning systems in $\alpha$ phase owing to the limited volume fraction of $\beta$ phase[11,44]. However, these models disregard the effect of the $\beta$ phase on deformation procedure which may lead to discrepancies between experiments and simulations[45]. Thus, both $\alpha$ and $\beta$ phases were considered in the here proposed model and subsequent simulations. Moreover, post-mortem and fracture surface analyses were performed on a tensile fractured sample. The results were directly compared focusing on the $\alpha / \beta$ plastic heterogeneities and fracture characteristics.

\section{Experimental Procedure}

\section{Sample preparation}

The Ti-6Al-4V (TA6V) sample with full lamellar microstructure was used in this work (see Fig. 1(a) and (b) ). The material was supplied by BaoTi Group Co.Ltd and had following chemical composition (in wt\%) 6.43Al, 4,21 V, 0.40Fe, 0.15Si, 0.10C, $0.05 \mathrm{~N}, 0.015 \mathrm{H}$, and bal. Ti. The $\beta$ transus temperature of the alloy is $995^{\circ} \mathrm{C} \pm 5^{\circ} \mathrm{C}[1]$. To obtain a uniform lamellar morphology, the material was treated in the $(\alpha+\beta)$ phase field. Subsequently, the material was heated to $960^{\circ} \mathrm{C}$ with 1 hour of holding time, followed by air cooling. Next, the material was aged at $540^{\circ} \mathrm{C}$ for 8 
hours followed by air cooling to ensure an equilibrium distribution of $\alpha / \beta$ phase.

According to Fig.1, the considered material exhibits a full lamellar structure before the deformations. Besides, a small quantity of $\beta$ laths embedded in the $\alpha$ lamellae can be observed. It can be observed that the width of $\alpha$ lamella varies $3 \mu \mathrm{m} \sim 5 \mu \mathrm{m}$, whereas $\beta$ lath seems to maintain the width less than $1 \mu \mathrm{m}$ (see Fig.1(c),(d) ).
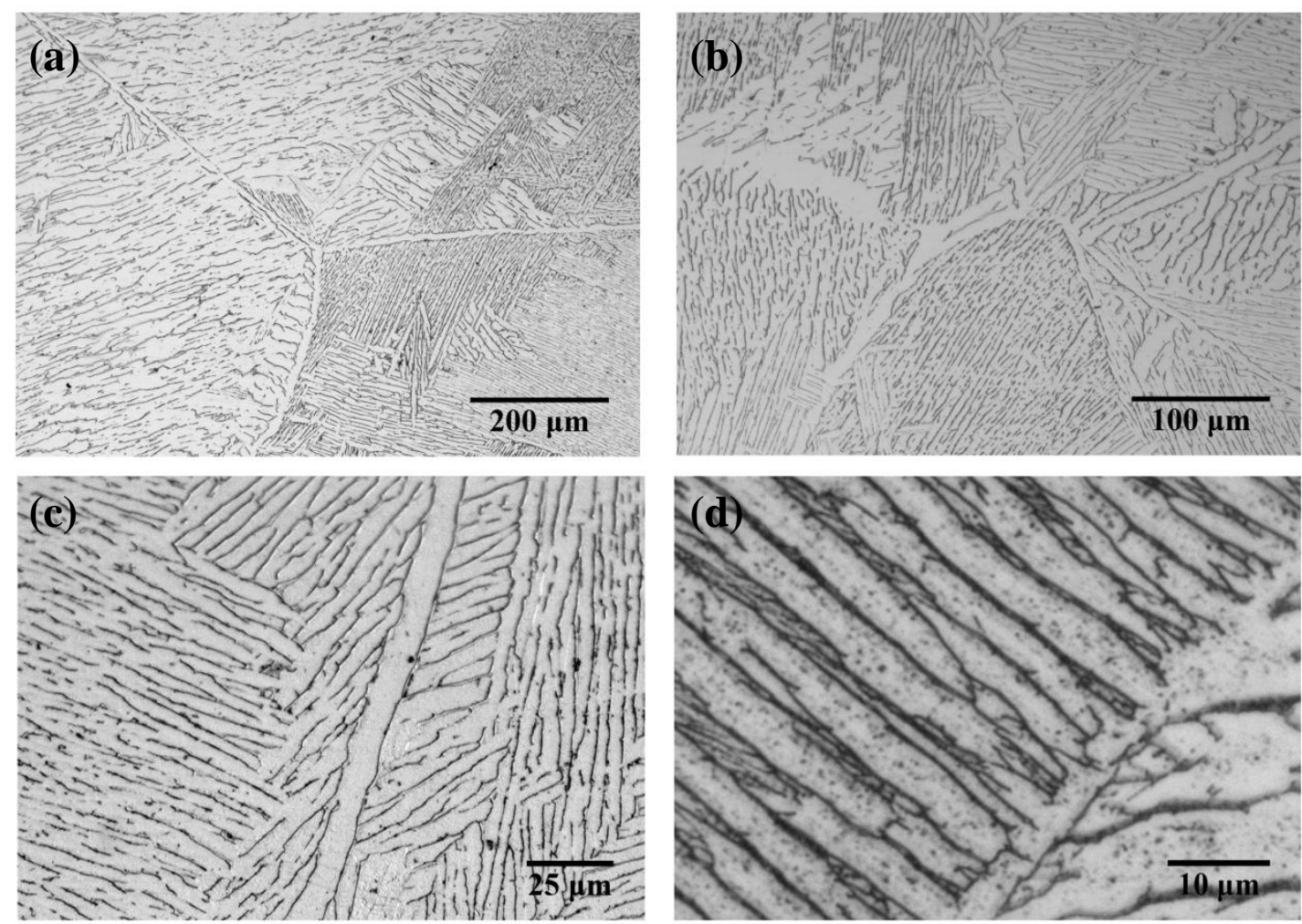

Fig.1. Microstructure morphology of Ti-6Al-4V before deformation in different magnifications; (a) $100 \times$, (b) $200 \times$, (c) $500 \times$, (d) 1000×. (Bright lamellae for $\alpha$ phase and dark laths for $\beta$ phase) 


\section{Fracture surface analysis and post-mortem SEM}

In the authors' previous studies[8,9], some tensile tests were completed; the results and details can be found in [8,9]. Only post-mortem fracture surface and cross-sectional microstructure observations were additionally performed here.

The fracture surfaces were characterized via a JSM-6010 scanning electron microscope(SEM). Then, the ruptured samples were embedded into an epoxy matrix with the tensile axis in the plane of the matrix, followed by a routine metallographic sample preparation procedure until the central plane appeared. Finally, polishing and subsequent etching were performed using a mixed solution of OP-S $+\mathrm{H}_{2} \mathrm{O}_{2}$ and Kroll's reagent $\left(1 \mathrm{ml} \mathrm{HF}+3 \mathrm{ml} \mathrm{HNO}_{3}+96 \mathrm{ml}\right.$ water $)$, respectively. The microstructure morphology and distribution were observed with an optical microscope(OM-Leica DM 4000) and SEM (Zeiss Supra 55VP).

\section{Simulation Procedure}

Crystal Plasticity simulation techniques can provide interesting information about the mechanical behavior of polycrystalline materials, based on interplay between phases, grains and sub-grains[18].

To analyze the influence of morphology and distribution of $\alpha / \beta$ phases 
on the stress/strain distribution and, subsequently, to predict the vulnerable sites for void nucleation and damage initiation, it is necessary to establish a CP model in accordance with the SEM image. Hereafter, by combining this simulation approach with our previous experiments, the local stress and strain evolution during plastic deformation can be determined.

\section{Isotropic-CP model creation}

Based on a realistic SEM image, a two dimensional (2D) FFT model was developed to analyze the distribution of stress/strain in $\alpha / \beta$ phases with the goal to predict the stress/strain behavior and failure mode of the Ti-6Al-4V alloy.

It is worth to note that, at the ambient temperatures, full lamellar microstructure morphology can be observed. Within one $\alpha$ grain/colony, all $\alpha$ lamellae exhibit parallel and equal crystallographic orientations. To alleviate the effect of the crystallographic orientation on plastic deformation, a local region within an $\alpha$ grain/colony (see Fig.2 ) can be selected to have $\alpha$ lamellae with the same original crystallographic orientation.

As shown in Fig.2, the image was imported in Image J[46,47] and threshold to distinguish between $\alpha$ phase(dark) and $\beta$ phase(bright). A code was written to identify and map the phases onto a matrix; one pixel 
of the image was assigned to one element of the matrix corresponding to the brightness of this pixel in the image (darkness and brightness for $\alpha$ phase and $\beta$ phase, respectively).

In addition, according to Schmid's law, it is necessary to consider the variations in the Schmid factors in modeling and simulation. The adapted method was as follows,

(1) The original image was rotated $45^{\circ}$ and $90^{\circ}$ clockwise;

(2) The same region was selected and processed for $0^{\circ}$ rotation;

(3) The "image to matrix" procedure was repeated.

It should be noted that in this study, the initial RVE region and rotating RVE region were marked as "Ori. 0 " $\left(0^{\circ}\right.$ rotation), "Ori. $45 "\left(45^{\circ}\right.$ rotation) and “Ori. $90^{\prime}$ " $\left(90^{\circ}\right.$ rotation), respectively. 

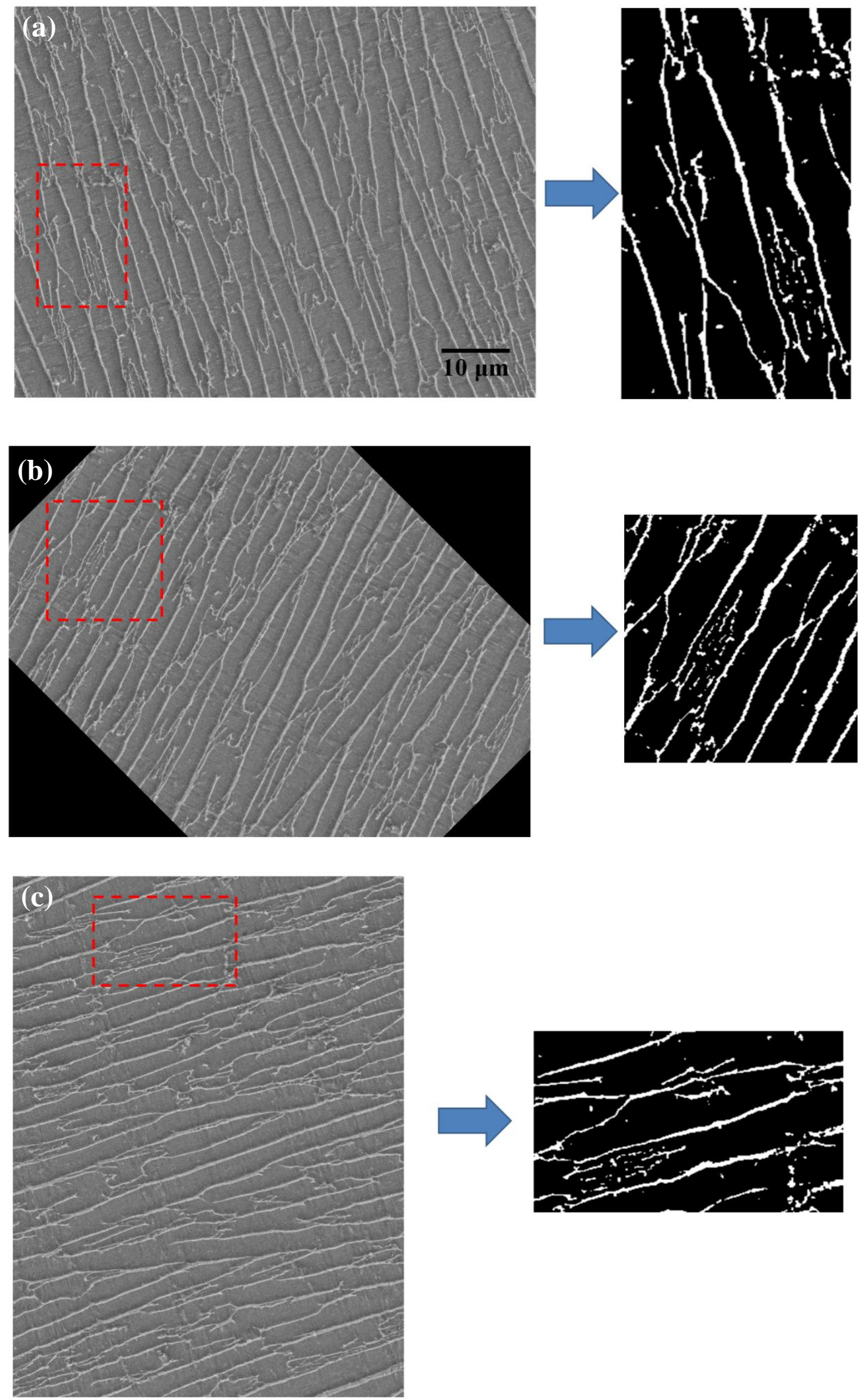
Fig.2. RVE modeling based on realistic image (a) $0^{\circ}$ rotation(Ori. 0), (b) $45^{\circ}$ rotation(Ori. 45), (c) $90^{\circ}$ rotation(Ori. 90)

Although the prediction accuracy of the model could be increased by exaggerating the mapping size, the model size depends on the computational capacity. In this study, a different rotating angle can result in different mapping areas. For $0^{\circ}, 45^{\circ}$ and $90^{\circ}$ rotations, the mapping regions are $182 \times 310$ pixels, $229 \times 244$ pixels and $310 \times 182$ pixels, respectively. In other words, the model sizes of these three mapping regions are on $182 \times 310 \times 1,229 \times 244 \times 1$ and $310 \times 182 \times 1$ grids, respectively.

At the end of this stage, the map was transferred to the numerical model implemented by Düsseldorf Advanced Material Simulation Kit (DAMASK) spectral solver.

\section{Isotropic crystal plasticity model}

The kinematics of the adapted constitutive model are based on the established continuum mechanical framework of elastoplasticity at finite strains [18].The total deformation gradient $\mathbf{F}$ can be decomposed into an elastic part and a plastic part;

$$
\mathbf{F}=\mathbf{F}_{\mathrm{e}} \mathbf{F}_{\mathbf{p}}
$$

where $\mathbf{F}_{\mathbf{e}}$ represents the elastic part that consists of elastic stretching and crystal lattice rotation, and $\mathbf{F}_{\mathbf{p}}$ denotes the plastic deformation gradient 
due to slip.

The development of the plastic deformation gradient can be expressed as

$$
\dot{\mathbf{F}}_{\mathrm{p}}=\mathbf{L}_{\mathbf{p}} \mathbf{F}_{\mathbf{p}}
$$

where $L_{\mathrm{p}}$ is the plastic velocity gradient due to dislocation glide and can be described as

$$
\mathbf{L}_{\mathbf{p}}=\dot{\mathbf{F}}_{\mathbf{p}}\left(\mathbf{F}_{\mathbf{p}}\right)^{-1}=\dot{\gamma}^{\alpha} \mathbf{m}^{\alpha} \otimes \mathbf{n}^{\alpha}
$$

where $\dot{\gamma}^{\alpha}, m^{\alpha}$, and $n^{\alpha}$ are shear rate, slip direction vector and normal vector of one slip system $\alpha$, respectively. $\mathbf{n}$ is the number of active slip systems. The shear rate, $\dot{\gamma}^{\alpha}$,can be defined as[48]

$$
\begin{aligned}
\dot{\gamma}^{\alpha} & =\dot{\gamma}_{0}\left|\frac{\tau^{\alpha}}{S^{\alpha}}\right|^{n} \operatorname{sgn}\left(\tau^{\alpha}\right) \\
\tau^{\alpha} & =\mathbf{S} \bullet\left(\mathbf{m}^{\alpha} \otimes \mathbf{n}^{\alpha}\right)
\end{aligned}
$$

where $\dot{\gamma}_{0}$ is a reference shear rate, $\tau^{\alpha}$, the resolved shear stress of $\alpha$ slip system, and $S^{\alpha}$, the corresponding critical resolved shear stress. The exponent $n$ represents the stress sensitivity (inverse rate sensitivity) of a dislocation slip.

During plastic deformation, the dislocation accumulation induces the strain hardening. The adapted hardening law is based on Ref.[49] and Ref. [50],

$$
\dot{S}^{\alpha}=h_{0}\left(1-\frac{S^{\alpha}}{S_{s}^{\alpha}}\right)^{a} q_{\alpha \beta}\left|\dot{\gamma}^{\beta}\right|
$$


where $h_{0}$ is the initial hardening parameter, $S_{s}^{\alpha}$ reflects the saturation stress for the $\alpha$ slip system; and $q_{\alpha \beta}$ is the latent hardening parameter with a value of 1.4.

As shown in Fig.2, a selected region was treated as RVE in the CP modeling by using the free and open source package DAMASK [39]. Since the RVE region was selected within one grain, i.e., misorientation was disregarded in this RVE an isotropic CP model was established in this study.

According to our previous work, no twinning was found during deformation[8,9]. Only slip systems activated in the $\alpha / \beta$ phases were considered. Therefore, a conventional phenomenological CP model [18,51], reassessed by Kalidindi et al[52], was implemented for the slip characteristics of hexagonal titanium. The tensile deformation simulations were carried out by a spectral method [53] within DAMASK $[39,43,53]$. The identified parameter set is presented in Table 1 . The loading rate was set to $10^{-3} \mathrm{~S}^{-1}$, and the direction was parallel to the horizon (X axis). 
Table 1 Materials parameters of CP modeling for (a) HCP $\alpha$ phase[54,55] and (b) BCC $\beta$ phase[11]

\begin{tabular}{|c|c|c|}
\hline Property & Value & Unit \\
\hline \multicolumn{3}{|c|}{ (a) $\boldsymbol{\alpha}$ phase (HCP) $[54,55]$} \\
\hline $\mathrm{C}_{11}$ & 160.0 & $\mathrm{GPa}$ \\
\hline $\mathrm{C}_{12}$ & 90.0 & $\mathrm{GPa}$ \\
\hline $\mathrm{C}_{13}$ & 66.0 & $\mathrm{GPa}$ \\
\hline $\mathrm{C}_{33}$ & 181.7 & $\mathrm{GPa}$ \\
\hline $\mathrm{C}_{44}$ & 46.5 & $\mathrm{GPa}$ \\
\hline$\dot{\gamma}_{0}$ & 0.001 & $\mathrm{~S}^{-1}$ \\
\hline $\mathrm{S}_{0}$ for basal slip & 349.3 & $\mathrm{MPa}$ \\
\hline $\mathrm{S}_{0}$ for prism slip & 150.0 & $\mathrm{MPa}$ \\
\hline $\mathrm{S}_{0}$ for pyramidal slip & 1107.9 & $\mathrm{MPa}$ \\
\hline $\mathrm{S}_{\mathrm{s}}$ for basal slip & 568.6 & $\mathrm{MPa}$ \\
\hline $\mathrm{S}_{\mathrm{s}}$ for prism slip & 1502.2 & $\mathrm{MPa}$ \\
\hline$S_{\mathrm{s}}$ for pyramidal slip & 3420.1 & $\mathrm{MPa}$ \\
\hline $\mathrm{h}_{0}$ & 200 & $\mathrm{MPa}$ \\
\hline $\mathrm{a}$ & 2 & / \\
\hline $\mathrm{n}$ & 20 & / \\
\hline \multicolumn{3}{|l|}{ (b) $\boldsymbol{\beta}$ phase (BCC)[11] } \\
\hline $\mathrm{C}_{11}$ & 250 & $\mathrm{GPa}$ \\
\hline $\mathrm{C}_{12}$ & 19 & $\mathrm{GPa}$ \\
\hline $\mathrm{C}_{44}$ & 230 & $\mathrm{GPa}$ \\
\hline$\dot{\gamma}_{0}$ & 0.0023 & $\mathrm{~S}^{-1}$ \\
\hline $\begin{array}{c}\mathrm{S}_{0}(\{110\}<111> \\
\quad \text { slip system })\end{array}$ & 500 & $\mathrm{MPa}$ \\
\hline $\begin{array}{c}\mathrm{S}_{0}(\{112\}<111> \\
\quad \text { slip system })\end{array}$ & 500 & $\mathrm{MPa}$ \\
\hline $\begin{array}{c}\mathrm{S}_{\mathrm{s}}(\{110\}<111> \\
\quad \text { slip system })\end{array}$ & 700 & $\mathrm{MPa}$ \\
\hline $\begin{array}{c}\mathrm{S}_{\mathrm{s}}(\{112\}<111> \\
\quad \text { slip system })\end{array}$ & 700 & $\mathrm{MPa}$ \\
\hline $\mathrm{h}_{0}$ & 200 & $\mathrm{MPa}$ \\
\hline $\mathrm{a}$ & 2 & / \\
\hline $\mathrm{n}$ & 20 & l \\
\hline
\end{tabular}




\section{Results}

\section{Microstructure morphology}

Fig.3 depicts the microstructure morphology of the sample that experienced plastic deformation. Adjacent to the fracture, the microstructure seems to maintain a lamellar morphology even after plastic deformation.

A "zig-zag" shape fracture trace can be found (marked by yellow dash line) in Fig.3(a), which infers that this material exhibits a ductile fracture. In addition, in the local region of the fracture zone, the trace seems to be long and straight instead of having a zig-zag shape. This can indicate existence of a brittle fracture mode (cleavage fracture) during damage development.

Fig.3(b) presents the microstructure morphology of the selected zone (green rectangle in Fig.3(a)). No obvious microstructure distortion can be observed in this region; both $\alpha$ lamellae and $\beta$ laths maintain the original morphology (see Fig.1). However, as depicted in Fig.3(c), obvious microstructure distortion can be clearly observed. This local region is adjacent to the fracture surface, which is marked by a small red circle in Fig.3(a). Both $\alpha$ lamellae and $\beta$ laths are distorted due to severe plastic deformation exists in this local region. 

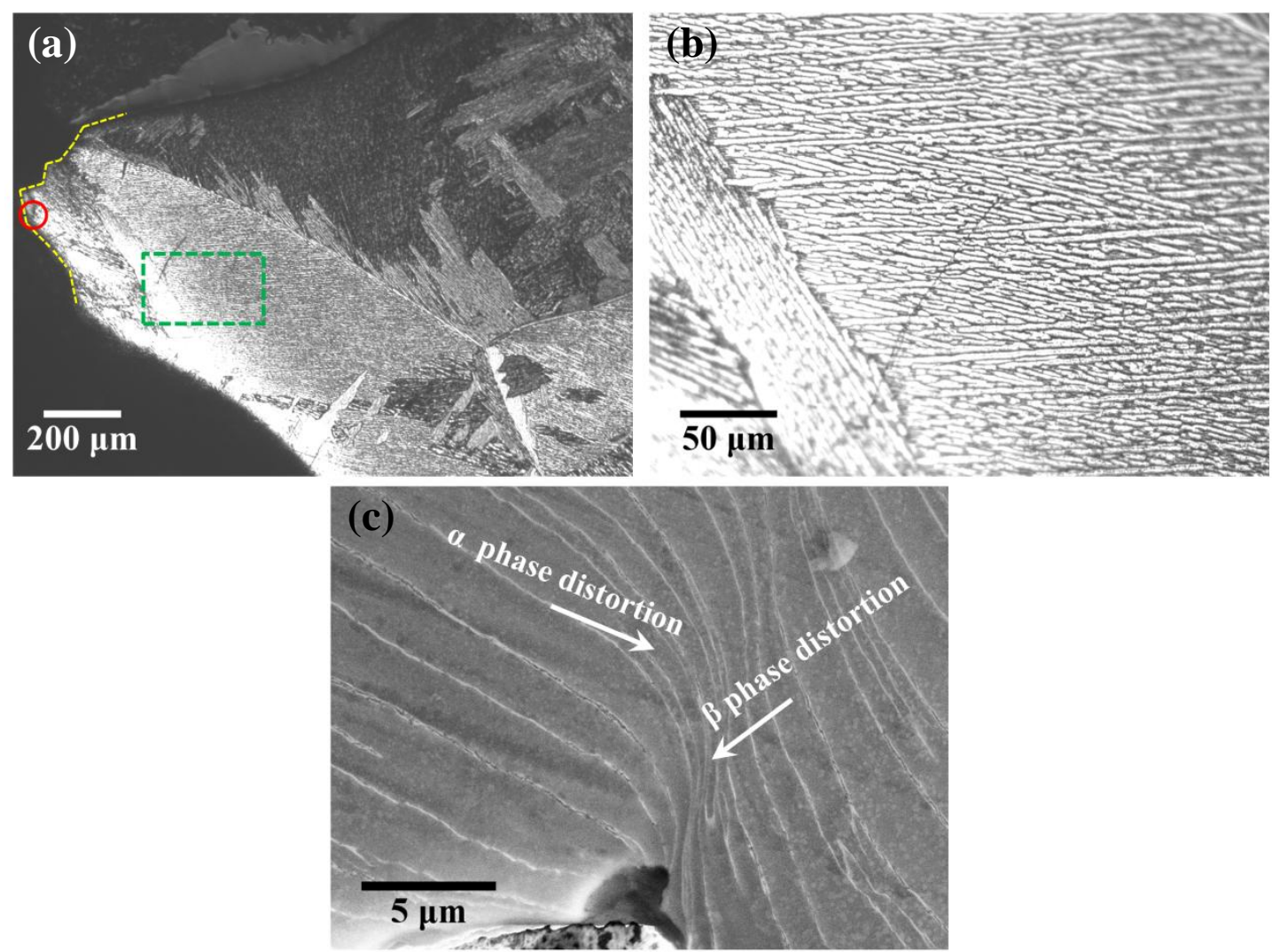

Fig.3. Microstructure morphology of TA6V sample after fractured, (a) low magnification, (b) selected area in (a) (green rectangle), (c) selected area in (a) (red circle)

In order to focus on variations in the microstructure morphology and distribution of voids in the vicinity of the fracture zone, SEM was implemented and the results are shown in Fig.4. The considered material exhibits a full lamellar structure with $\alpha$ lamellae of thickness of $3 \sim 5 \mu \mathrm{m}$. However, in some local regions, obvious $\alpha / \beta$ phase distortions can be noticed, due to the occurrence of severe local plastic deformations (see the upper right part of Fig.4(a) ). Moreover, adjacent to the ruptured surface, arrays of voids can be observed within the $\alpha$ lamellae, which are aligned in the direction of the $\alpha$ phase; the $\beta$ phase still exists in the form 
of $\beta$ laths (see Fig.4(a)).

Furthermore, to analyze the interaction between voids propagation and microstructure morphology, the frontier area, which contains the front edges for void propagation, was selected and marked with a yellow rectangle in Fig.4(a). The magnified area is presented in Fig.4(b). Compared with other areas, the void density in $\beta$ laths bifurcation area seems to be higher (see white arrows in Fig.4(b) ). This might be caused because void initiations are favored at the bifurcations of $\beta$ laths. In addition, approximately all void arrays tend to nucleate and propagate along the $\alpha$ lamellae rather than "breaking" the $\beta$ laths. In other words, the $\beta$ laths could act as "walls" that separate two neighboring arrays. This is further proved by the unbroken $\beta$ laths, whereas plenty of broken $\alpha$ lamellae can be observed in Fig.4 (a).

The same results can be noticed in Fig.4(c) and (d). High density of voids can be found in $\beta$ bifurcation regions, which means these bifurcation regions are vulnerable sites for void nucleation and propagation. 

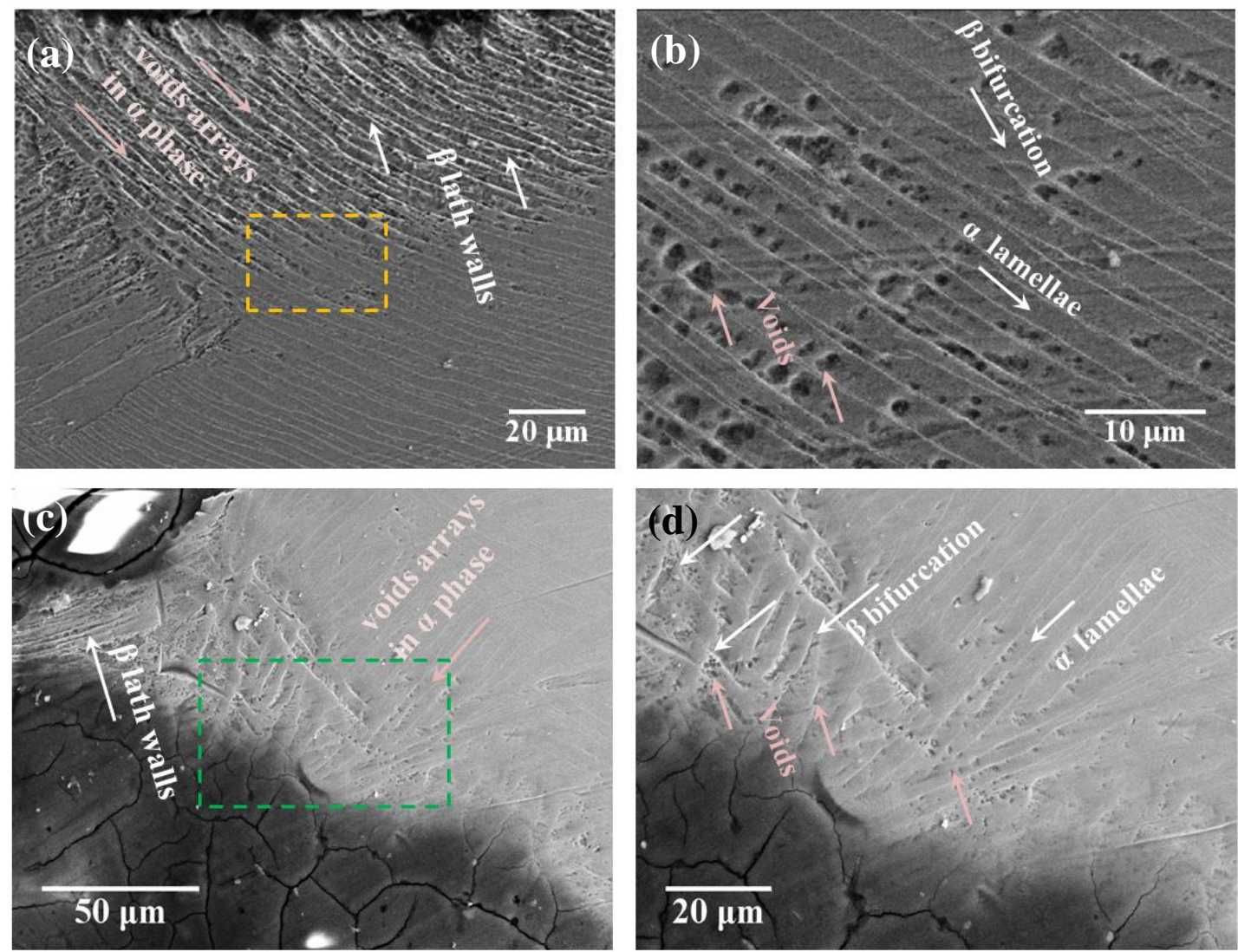

Fig.4. Microstructure morphology and voids distribution adjacent to fracture zone in (a) and(c); (b) selected region in (a); (d) selected region in (c).

\section{Fractography}

Fig.5 presents the morphology of the fractured surface; several fracture features can be noticed in Fig.5(a), including cleavage facets and tear ridge, which are usually considered as typical cleavage fracture features (brittle fracture). Further, dimples can be observed, which are characteristic for a ductile fracture. Thus, it can be assumed that this material has ruptured in a hybrid mode (brittle and ductile damages). The regions containing cleavage facets and tear ridge were analyzed individually, as shown in Fig.5(c) (d) and Fig.5(e) (f), respectively. 

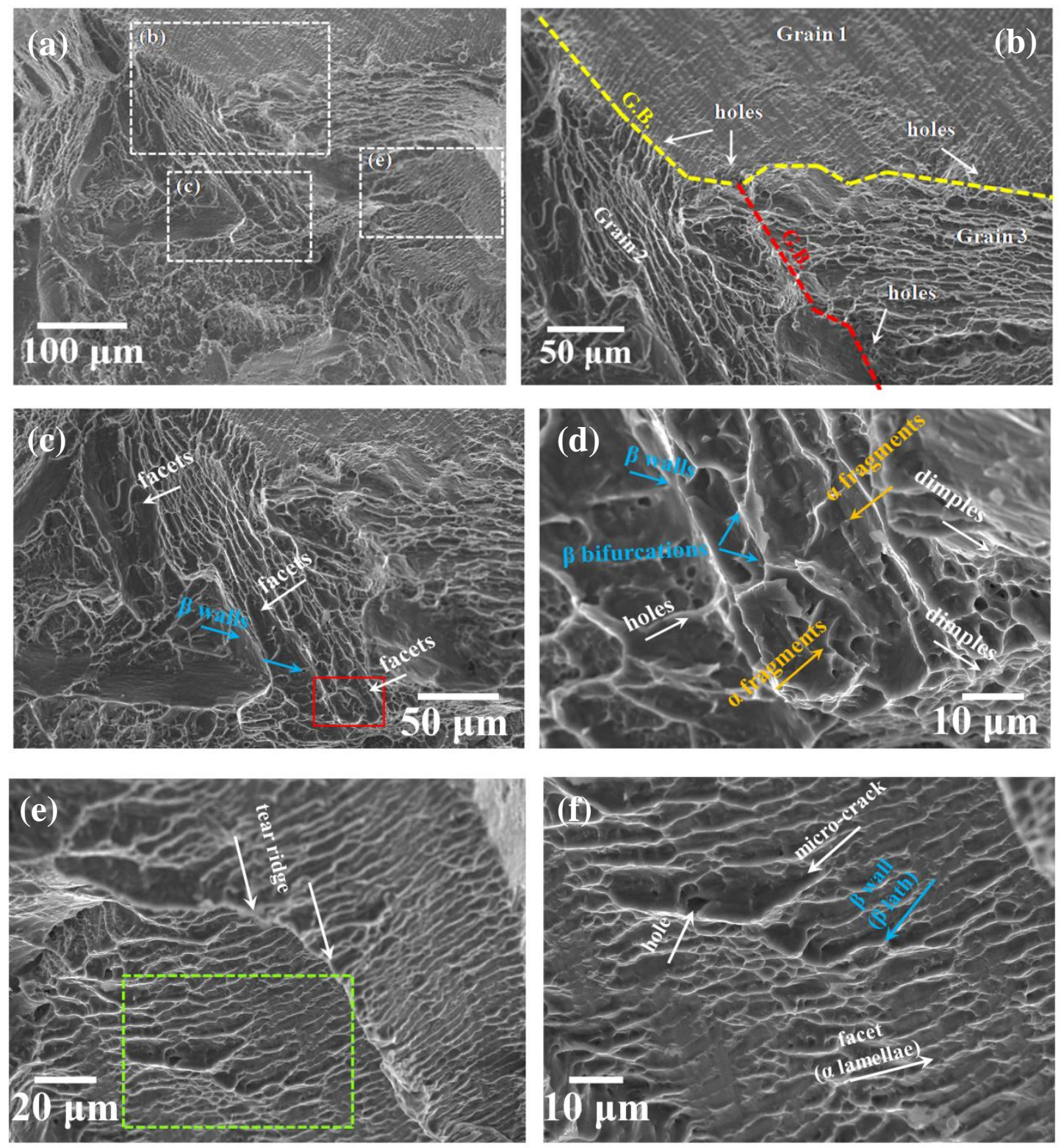

Fig.5. Fractographs of ruptured sample; (a) macro-scale fracture surface morphology, (b), (c) and (e) selected area in (a); (d) and (f) selected area in (c) and (e), respectively.

Fig.5(b) presents the morphology around the junction of $\alpha$ grains or colonies. Please note that in this study, both $\alpha$ grains and $\alpha$ colonies were treated as grains since they behave approximately equally during damage evolution. As shown in Fig.5(b), different fracture characteristics can be seen in different grains. In Grain 1, only cleavage facets can be observed. The facets exhibit a lamella-like morphology with some distortions, 
which can be associated with $\alpha$ lamellae. In Grain 2 and Grain 3, elongated dimples and facets exist. In addition, the dimples in Grain 2 and Grain 3 exhibit different elongation directions, which could be related to different stress/strain distributions owing to dissimilar initial orientations.

Regarding the boundaries, the holes (voids) tend to distribute at the boundary of $\alpha$ grains (grain boundaries are marked by red and yellow dash lines). Typically, a high hole density exists at the triple junction of boundaries (indicated by white arrows). According to Ref.[55,56], these holes can be treated as voids. Thus, the grain boundaries or colony boundaries, as well as the junction of boundaries, could be a vulnerable site for void initiation and evolution.

Fig.5(c) depicts a region selected from Fig.5(a) with cleavage damage features and dimples. Some cleavage facets exist on the fracture surface (marked by white arrows) and have a plate-like aspect, which could be linked to coarse $\alpha$ lamellae. Besides, $\beta$ "walls" can be found between two neighboring facets (indicated by blue arrows). The dimples seem to be elongated along the plate-like facets. In order to analyze the cleavage facets more profoundly, one region within the facet was selected (marked by red rectangle in Fig.5(c) ) and is shown in Fig.5(d).

In Fig.5(d), more complex characteristics can be observed; elongated dimples and their precursors - holes (voids), exist (indicated by white 
arrows) with widths of $5 \mu \mathrm{m} \sim 8 \mu \mathrm{m}$ and less than $3 \mu \mathrm{m}$, respectively. The size of holes(voids) is comparable with the thicknesses of $\alpha$ lamellae(3 5 $\mu \mathrm{m})$. Within the facets, dimples, holes, $\beta$ walls and bifurcations exist. These results seem to agree well with the void distribution in transverse view (see Fig.4 ).Simultaneously, $\alpha$ fragments exist within the facets in particular at $\beta$ bifurcations which will be discussed in the following section.

In Fig.5(e), a tear ridge and the facets can be observed, which may be cleavage features. The tear ridge may result from the boundary of two neighboring $\alpha$ grains with distinct misorientation. Moreover, $\beta$ walls and bifurcations also exist between facets. Please note that all facets exhibit a plate-like morphology and tend to lie parallel to each other. In addition, the widths of these facets are approximately $5 \mu \mathrm{m}$. As mentioned above, the facets could be linked to damaged $\alpha$ lamellae. Further, holes, which could be treated as precursors of dimples, can be found within the facets.

If focusing on the holes, one region was selected (marked by green rectangle in Fig.5(f) ). Within the facets(linked to $\alpha$ lamellae), the holes tend to distribute at the bottom of $\beta$ walls. Thus, a void could originate at the interface of $\alpha / \beta$ phases and propagate along this interface. This assumption agrees well with the results of our previous work $[8,9]$. Moreover, one micro-crack with holes inside can be observed (pointed out by white arrow in Fig.5(f) ). This micro-crack can be linked to the 
coalescence of neighboring void arrays caused by stress/strain concentration; $\beta$ walls could break during the coalescence. Further, micro-cracks may coalesce to form meso-crack or macro-crack until failure of this material.

\section{CP simulations}

According to the microstructure morphology and fractography, the $\alpha$ lamellae and $\beta$ laths could play different roles during damage evolution. The $\alpha$ lamellae tend to break to form facets, whereas $\beta$ lath maintain the original morphology and separate facets (see Fig.4 and Fig.5 ). This could be attributed to the heterogeneous stress distribution in the $\alpha / \beta$ phases, which results from the plastic incompatibility of $\alpha / \beta$ phases.

In order to analyze the behavior of the $\alpha / \beta$ phases, a realistic modeling and simulation technique was implemented. In Ref.[56] and [57], an RVE model for Ti alloy on the basis of real images was established. However, only one $\alpha / \beta$ phase orientation was considered for polycrystalline material. Therefore, the model disregards the influence of variation in orientation of stress/strain distribution.

Thus, variations in Schmid factors were considered in this current simulation. The results are presented in Fig.6 created with open source software ParaView[58,59]. For all initial orientations, heterogeneous stress/strain distributions in the $\alpha$ phase(dark phase) and $\beta$ phase(bright 
phase) can be observed. Furthermore, stress concentrates in the regions adjacent to the interface of the $\alpha / \beta$ phases, in particular in the vicinity of $\beta$ bifurcations.

Fig.6 (a) (c) illustrate the stress and strain map for the Ori.0 status $\left(0^{\circ}\right.$ rotation). In the map of components $\sigma_{x x}$ and $\sigma_{M}$ (see Fig.6(a) and (b) ), owing to the plastic-deformation incompatibilities of the $\alpha$ and $\beta$ phases, the plastic-interaction stresses in the $\alpha$ and $\beta$ phases are different; the $\alpha$ phase exhibit tensile stress, whereas it is the corresponding compressive interaction stress in the $\beta$ phase.

These results are in a good agreement with the observations in Ref.[60,61]. Moreover, in Ref. [60,61], it was indicated that the crack initiation can be probably promoted by tensile interaction stress. Owing to the plastic-deformation incompatibilities, a high-stress barrier is introduced at interface of $\alpha / \beta$ phases for slip transmission, which could cause high-density dislocations that pile up along the interface[62]. Subsequently, higher strain concentrations at the $\alpha / \beta$ interface could result in local regions that are favorable for void initiation.

As shown in the strain distribution map (in Fig.6(c) ), "wrinkles" that might be related to the deformation bands exist in $\alpha$ lamellae, with an inclining angle of approximately $45^{\circ}$ with respect to the direction of deformation. These observations may reflect the indications in the authors' previous work[9], which investigated the formation of shear bands within 
one grain. Strain in particular prefers to concentrate at bifurcations of the $\beta$ phase, which can be interpreted using Ref.[62] and [63]. Moreover, our results agree well with the observation of a high void density close to bifurcations (shown in Fig.4(b) and Fig.5(d) ).

The same results can be found for Ori. $45^{\circ}\left(45^{\circ}\right.$ rotation $)$, as shown in Fig.6(d) (f). A stress concentration occurs along the $\alpha / \beta$ interface especially at $\beta$ bifurcations in the forms of tensile interaction stress(see Fig.6(d) ). According to the lower left part of Fig.6(f), a severe strain concentration can be found at $\beta$ bifurcations. Further, the "wrinkles" seem to be inclined about $45^{\circ}$ with respect to the deformation direction.

However, the simulated results for Ori. $90^{\circ}\left(90^{\circ}\right.$ rotation $)$ exhibit the opposite behavior(Fig.6(g) (i) ). The $\alpha$ phase exhibits compressive interaction stress, whereas it is the corresponding tensile interaction stress in the $\beta$ phase(see Fig.6(g) ). Therefore, the initial orientation significantly affected the deformation behavior. In other words, the variations in the Schmid factor induce different plastic stress/strain distributions within one grain. Regarding the von Mises stress/strain distribution ( in Fig.6(h) (i) ), the results are comparable to those of Ori.0 and Ori.45.Therefore, with the help of the simulation results, the different fracture surface morphologies for neighboring grains shown in Fig.5(b) can be interpreted.

In order to further investigate this fracture behavior, it is necessary to 
add crystallographic orientation information into the simulation with the help of Electron Backscattered Diffraction technique(EBSD). This work will be conducted in the future.
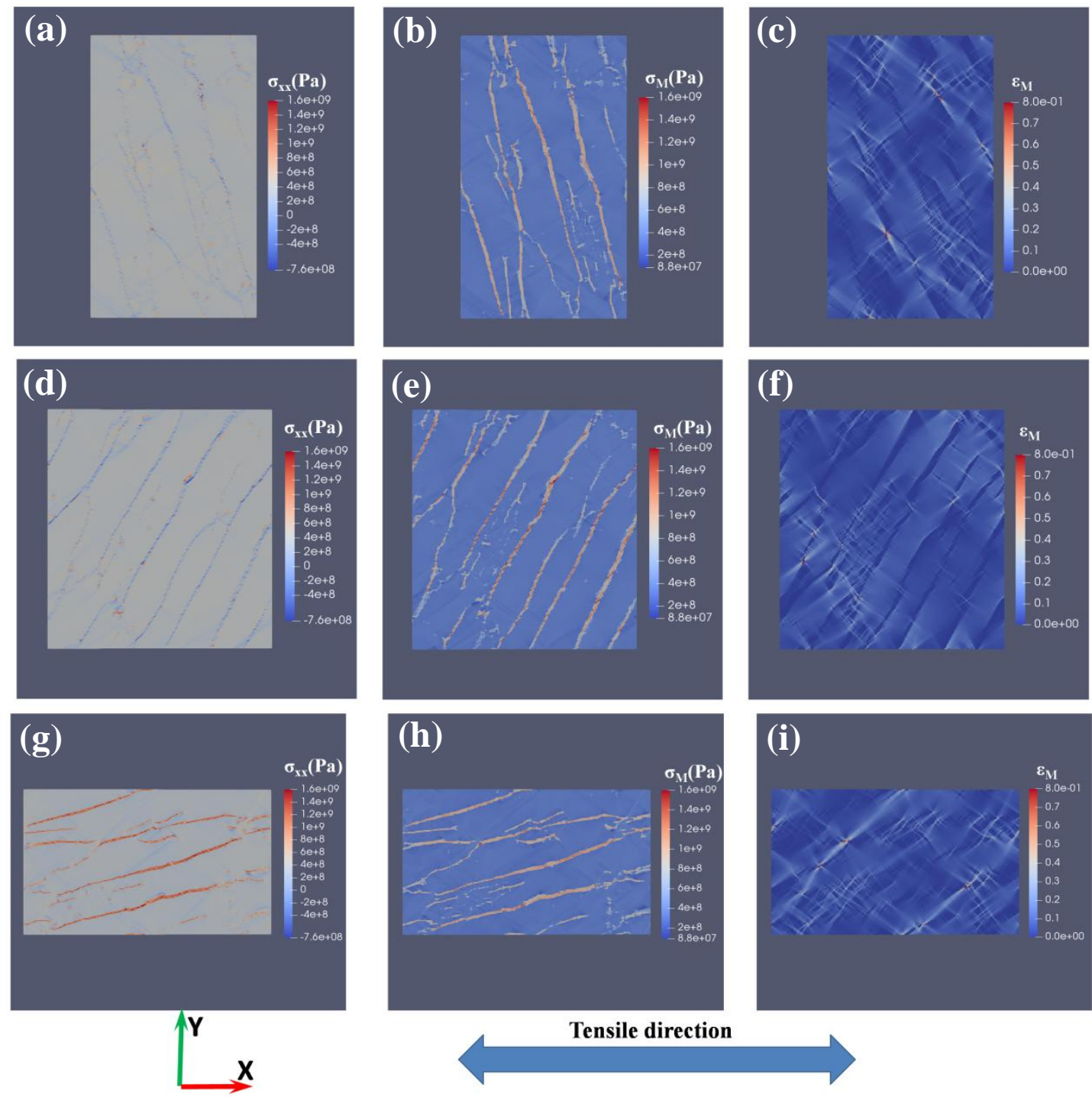

Fig.6. Results from the simulations performed using RVE with 5.0\% equivalent strain; (a) (c) for Ori.0; (d) (f) for Ori.45; (g) (i) for Ori.90. $\sigma_{\mathrm{M}}$ and $\varepsilon_{\mathrm{M}}$ refer to von Mises stress and strain, respectively.

\section{Discussion}

Evidently, void evolution and fracture morphology are related to the 
microstructure. As shown in Fig.3(a), a zig-zag shape can be found in the fracture zone. Furthermore, in the fractographs (shown in Fig.5), cleavage ductile characteristics, holes (precursors of dimples), and $\alpha$ phase fragments within cleavage facets can be observed. Apparently, material ruptured in a hybrid fracture mode.

Hybrid fracture modes have been investigated in Ref.[56,62-64]. However, these studies did not explore the micro-mechanism of this fracture mode intensively.

According to Ref. [4-6,65], voids can nucleate along an $\alpha / \beta$ interface, owing to a decohesion between the $\alpha$ and $\beta$ phases. Generally, the $\beta$ phase could be considered as being composed of "hard" particles inserted into a "soft" matrix( $\alpha$ phase $)[5,6,65]$. According to Ref. [66], slip bands originate at the soft $\alpha$ phase near the $\alpha / \beta$ interface. Subsequently, the soft $\alpha$ phase starts plastic deformation firstly and is more highly strained than the $\beta$ phase[60,62,65-68].

As indicated in Ref.[65], plastic strain accumulates at the interface of the $\alpha / \beta$ phases and the plastic incompatibility makes the interface a favorable site for void initiation. Besides, the void nucleation is not only driven by plastic strain, but by plastic interaction stress as well, as revealed via FEM simulation.

Based on post-mortem work SEM and FEM simulation for fracture surfaces[65], it was considered that void initiate because of 
particle/matrix interface decohesion. The position and shape of the voids are depended on the hard particle orientations (perpendicular or parallel to the tensile-stress direction).

These results are in a good agreement with the simulations results of this work, shown in Fig.6 (Ori. $0^{\circ}$ and Ori.90 $)$. According to the von Mises stress distribution(see Fig.6(b),(e),and(h) ), stress concentration occurs at the interface of $\alpha / \beta$ phases, which could lead to a decohesion of the particle/matrix interface, and consequently to void initiation(see Fig.4).

In the propagation procedure, voids can propagate and coalesce to form local micro-cracks along the $\alpha$ lamellae until it ruptures. Particularly, at the frontier of the advancing voids (shown in Fig.4) $\alpha$ lamellae broke via voids coalescence and micro-crack formation. Regarding the hard $\beta$ laths, lath-like morphology was maintained which acts as "wall" to separate arrays of voids or micro-cracks in two neighboring $\alpha$ lamellae (white arrows in Fig.4(a) and blue arrows in Fig.5(c) ), even if $\alpha$ lamellae are fractured.

Regarding the observations in Fig.4 and the fracture surface morphologies(in Fig.5 ), the cleavage facets exhibit approximately the same morphology and width as the $\alpha$ lamellae(in particular, in Fig.5(b),(c)and(e) ). Thus, the cleavage facet may be induced by micro-crack propagation and the rupture of $\alpha$ lamellae. Moreover, the 
dimples and holes could be linked to voids evolution. The dimples can be treated as the growth and coalescence of voids according to the observations of the dimples elongating along facets in Fig.5(c) and (d). According to Ref.[56][65], holes could be linked to voids or precursors of dimples.

Consequently, the hybrid facture mode could be induced by void development. If an $\alpha$ lamella is completely filled with voids/micro-cracks, the lamella can be fractured and act as cleavage facet in the fractographs(see Fig.5 (e)\&(f) ). By contrast, if voids do not completely evolve from one $\alpha$ lamella, elongated dimples can be observed instead of facets. Further, undeveloped voids exist in the form of holes within the facets(shown in Fig.5(c)\&(d) ).

The orientations of the $\alpha$ lamellae ( $\alpha$ grains) play a significant role during plastic deformation and void development, as proved by the fracture surface morphologies shown in Fig.5(b). In order to investigate the influence of orientations (including crystallographic orientations) polycrystalline anisotropy will be considered in the $\mathrm{CP}$ model by using EBSD and DAMASK in the future.

\section{Conclusions}

An integrated experimental-numerical method has been implemented to 
analyze the origin of hybrid damages in the $(\alpha+\beta)$ Ti-6Al-4V alloy, which exhibits brittle characteristics (cleavage facets) and ductile features (dimples). The following observations have been made:

(1) Owing to microstructure inhomogeneities, the stress/strain tends to distribute heterogeneously in the $\alpha / \beta$ phases, which could make the interface of the $\alpha / \beta$ phases a vulnerable site for void nucleation.

(2) Severe stress/strain concentrations in $\beta$ lath bifurcation areas induce high void densities. In addition, a hard $\beta$ lath acts as a wall that separates two neighboring void arrays.

(3) The cleavage facets could be linked to ruptured $\alpha$ lamellae caused by a development of voids. The $\alpha$ lamellae can be fractured owing to voids coalescence which completely fill the lamellae.

(4) The orientations of $\alpha$ grains can affect the void evolution by influencing the stress/strain distribution during plastic deformation, This was proved by different fracture surface morphologies for neighboring grains.

\section{Acknowledgement}

The authors are grateful for the financial support by International Science and Technology Cooperation Program of China (No.2015DFA51430), National Natural Science Foundation of China (NSFC, No. 51671012, 51671007 and 51401010) and Aeronautical Science Foundation of China 
(No.2015ZF51069) for this study. The authors would also like to thank Dr.

Franz Roters and Dr. Martin Diehl of the Max-Planck-Institutfür

Eisenforschung $\mathrm{GmbH}$, for their kind support with the DAMASK code and helpful suggestions for the simulations.

\section{Compliance with ethical standards}

\section{Conflict of interest}

The authors declare that they have no conflict of interest.

\section{References}

[1] M. Peters, J. Kumpfert, C.H. Ward, C. Leyens, Titanium and Titanium Alloys: Fundamentals and Applications, Wiley-VCH Verlag GmbH \& Co. KGaA2005.

[2] R. Boyer, G. Welsch, E.W. Collings, Materials Properties Handbook: Titanium Alloys, ASM International1994.

[3] M.T. Jia, D.L. Zhang, B. Gabbitas, J.M. Liang, C. Kong, A novel Ti-6Al-4V alloy microstructure with very high strength and good ductility, Scripta Materialia 107 (2015) 10-13.

[4] J. Faleskog, C.F. Shih, Micromechanics of coalescence-I. Synergistic effects of elasticity, plastic yielding and multi-size-scale voids, Journal of the Mechanics and Physics of Solids 45(1) (1997) 21-50.

[5] A.L. Helbert, X. Feaugas, M. Clavel, The influence of stress trlaxiality on the damage mechanisms in an equiaxed $\alpha / \beta$ Ti-6AI-4V alloy, Metallurgical and Materials Transactions A 27(10) (1996) 3043-3058.

[6] W. Tirry, F. Coghe, S. Bouvier, M. Gasperini, L. Rabet, D. Schryvers, A multi-scale characterization of deformation twins in Ti6Al4V sheet material deformed by simple shear, Materials Science and Engineering: A 527(16) (2010) 4136-4145.

[7] A. Pineau, A.A. Benzerga, T. Pardoen, Failure of metals I: Brittle and ductile fracture, Acta Materialia 107 (2016) 424-483.

[8] N. Dang, L. Liu, E. Maire, J. Adrien, S. Cazottes, W. Xiao, C. Ma, 1. Zhou, 
Analysis of shear stress promoting void evolution behavior in an $\alpha / \beta$ Ti alloy with fully lamellar microstructure, Materials Science and Engineering A 737 (2018) 27-39. [9] N. Dang, L. Liu, E. Maire, J. Adrien, S. Cazottes, W. Xiao, C. Ma, L. Zhou, Three dimensional X-ray tomographic analysis of crack nucleation and growth by void coalescence in an $\alpha / \beta$ titanium alloy with lamellar microstructure, Materials Science and Engineering A (2018) (Under Review).

[10] S.E. Schoenfeld, B. Kad, Texture effects on shear response in Ti-6Al-4V plates, International Journal of Plasticity 18(4) (2002) 461-486.

[11] J. Thomas, M. Groeber, S. Ghosh, Image-based crystal plasticity FE framework for microstructure dependent properties of Ti-6Al-4V alloys, Materials Science and Engineering A 553(36) (2012) 164-175.

[12] V. Hasija, S. Ghosh, M.J. Mills, D.S. Joseph, Deformation and creep modeling in polycrystalline Ti-6Al alloys, Acta Materialia 51(15) (2003) 4533-4549.

[13] A.S. Khan, Y.S. Suh, R. Kazmi, Quasi-static and dynamic loading responses and constitutive modeling of titanium alloys, International Journal of Plasticity 20(12) (2004) 2233-2248.

[14] D. Deka, D.S. Joseph, S. Ghosh, M.J. Mills, Crystal plasticity modeling of deformation and creep in polycrystalline Ti-6242, Metallurgical and Materials Transactions A 37(5) (2006) 1371-1388.

[15] G. Venkatramani, S. Ghosh, M. Mills, A size-dependent crystal plasticity finite-element model for creep and load shedding in polycrystalline titanium alloys, Acta Materialia 55(11) (2007) 3971-3986.

[16] A.S. Khan, R. Kazmi, B. Farrokh, Multiaxial and non-proportional loading responses, anisotropy and modeling of Ti-6Al-4V titanium alloy over wide ranges of strain rates and temperatures, International Journal of Plasticity 23(6) (2007) 931-950.

[17] F.P.E. Dunne, D. Rugg, A. Walker, Lengthscale-dependent, elastically anisotropic, physically-based hcp crystal plasticity: Application to cold-dwell fatigue in Ti alloys, International Journal of Plasticity 23(6) (2007) 1061-1083.

[18] F. Roters, P. Eisenlohr, L. Hantcherli, D.D. Tjahjanto, T.R. Bieler, D. Raabe, Overview of constitutive laws, kinematics, homogenization and multiscale methods in crystal plasticity finite-element modeling: Theory, experiments, applications, Acta Materialia 58(4) (2010) 1152-1211.

[19] A. Shahba, S. Ghosh, Crystal plasticity FE modeling of Ti alloys for a range of strain-rates. Part I: A unified constitutive model and flow rule, International Journal of Plasticity 87 (2016) 48-68.

[20] E.P. Busso, F.T. Meissonnier, N.P. O'Dowd, Gradient-dependent deformation of two-phase single crystals, Journal of the Mechanics and Physics of Solids 48(11) (2000) 2333-2361.

[21] K.S. Cheong, E.P. Busso, Effects of lattice misorientations on strain heterogeneities in FCC polycrystals, Journal of the Mechanics and Physics of Solids 54(4) (2006) 671-689.

[22] H. Gao, Y. Huang, W.D. Nix, J.W. Hutchinson, Mechanism-based strain gradient plasticity- I. Theory, Journal of the Mechanics and Physics of Solids 47(6) (1999) 1239-1263. 
[23] N.A. Fleck, G.M. Muller, M.F. Ashby, J.W. Hutchinson, Strain gradient plasticity: Theory and experiment, Acta Metallurgica Et Materialia 42(2) (1994) 475-487.

[24] D. Kuhlmannwilsdorf, The theory of dislocation-based crystal plasticity, Philosophical Magazine A 79(4) (1999) 955-1008.

[25] C. Rehrl, B. Völker, S. Kleber, T. Antretter, R. Pippan, Crystal orientation changes: A comparison between a crystal plasticity finite element study and experimental results, Acta Materialia 60(17) (2012) 2379-2386.

[26] D.S. Li, S. Ahzi, S. M'Guil, W. Wen, C. Lavender, M.A. Khaleel, Modeling of deformation behavior and texture evolution in magnesium alloy using the intermediate $\phi$-model, International Journal of Plasticity 52 (2014) 77-94.

[27] L. Yao, Y. Wei, A polycrystal based numerical investigation on the temperature dependence of slip resistance and texture evolution in magnesium alloy AZ31B, International Journal of Plasticity 55(2) (2014) 80-93.

[28] C. Zhang, H. Li, P. Eisenlohr, W. Liu, C.J. Boehlert, M.A. Crimp, T.R. Bieler, Effect of realistic 3D microstructure in crystal plasticity finite element analysis of polycrystalline Ti-5Al-2.5Sn, International Journal of Plasticity 69 (2015) 21-35.

[29] J.D. Clayton, Dynamic plasticity and fracture in high density polycrystals: constitutive modeling and numerical simulation, Journal of the Mechanics and Physics of Solids 53(2) (2005) 261-301.

[30] M. Anahid, M.K. Samal, S. Ghosh, Dwell fatigue crack nucleation model based on crystal plasticity finite element simulations of polycrystalline titanium alloys, Journal of the Mechanics and Physics of Solids 59(10) (2011) 2157-2176.

[31] J. Cheng, S. Ghosh, A crystal plasticity FE model for deformation with twin nucleation in magnesium alloys, International Journal of Plasticity 67 (2015) 148-170. [32] F. Roters, D.I.P. Eisenlohr, T.R. Bieler, D. Raabe, Crystal Plasticity Finite Element Methods: In Materials Science and Engineering, 2010.

[33] R.A. Lebensohn, A.K. Kanjarla, P. Eisenlohr, An elasto-viscoplastic formulation based on fast Fourier transforms for the prediction of micromechanical fields in polycrystalline materials, International Journal of Plasticity 32-33 (2012) 59-69.

[34] R.A. Lebensohn, N-site modeling of a 3D viscoplastic polycrystal using Fast Fourier Transform, Acta Materialia 49(14) (2001) 2723-2737.

[35] M. Knezevic, H.F. Al-Harbi, S.R. Kalidindi, Crystal plasticity simulations using discrete Fourier transforms, Acta Materialia 57(6) (2009) 1777-1784.

[36] S. Ghosh, A. Shahba, X. Tu, E.L. Huskins, B.E. Schuster, Crystal plasticity FE modeling of $\mathrm{Ti}$ alloys for a range of strain-rates. Part II: Image-based model with experimental validation, International Journal of Plasticity 87 (2016) 69-85.

[37] H. Moulinec, P. Suquet, A numerical method for computing the overall response of nonlinear composites with complex microstructure, Computer Methods in Applied Mechanics \& Engineering 157(1-2) (1998) 69-94.

[38] H. Moulinec, A fast numerical method for computing the linear and nonlinear mechanical properties of composites, C.r Acad.sci.paris 318(11) (1994) 1417-1423.

[39] F. Roters, P. Eisenlohr, C. Kords, D.D. Tjahjanto, M. Diehl, D. Raabe, DAMASK: the Dusseldorf Advanced MAterial Simulation Kit for studying crystal plasticity using an FE based or a spectral numerical solver, Proc Iutam 3 (2012) 3-10. 
[40] S.B. Lee, R.A. Lebensohn, A.D. Rollett, Modeling the viscoplastic micromechanical response of two-phase materials using Fast Fourier Transforms, International Journal of Plasticity 27(5) (2011) 707-727.

[41] R.A. Lebensohn, A.D. Rollett, P. Suquet, Fast fourier transform-based modeling for the determination of micromechanical fields in polycrystals, Jom 63(3) (2011) 13-18.

[42] A.K. Kanjarla, R.A. Lebensohn, L. Balogh, C.N. Tomé, Study of internal lattice strain distributions in stainless steel using a full-field elasto-viscoplastic formulation based on fast Fourier transforms, Acta Materialia 60(6-7) (2012) 3094-3106.

[43] P. Eisenlohr, M. Diehl, R.A. Lebensohn, F. Roters, A spectral method solution to crystal elasto-viscoplasticity at finite strains, International Journal of Plasticity 46(7) (2013) 37-53.

[44] T. Maiti, P. Eisenlohr, Fourier-based spectral method solution to finite strain crystal plasticity with free surfaces, Scripta Materialia 145 (2018) 37-40.

[45] J.A. Moore, N.R. Barton, J.N. Florando, R. Mulay, M. Kumar, Crystal plasticity modeling of $\beta$ phase deformation in Ti-6Al-4V, Modelling and Simulation in Materials Science and Engineering 25(7) (2017).

[46] C.T. Rueden, J. Schindelin, M.C. Hiner, B.E. DeZonia, A.E. Walter, E.T. Arena, K.W. Eliceiri, ImageJ2: ImageJ for the next generation of scientific image data, BMC Bioinformatics 18(1) (2017) 529.

[47] B. Schmid, J. Schindelin, A. Cardona, M. Longair, M. Heisenberg, A high-level 3D visualization API for Java and ImageJ, BMC Bioinformatics 11(1) (2010) 274.

[48] J.W. Hutchinson, Bounds and Self-Consistent Estimates for Creep of Polycrystalline Materials, Proceedings of the Royal Society A Mathematical Physical and Engineering Sciences 348(348) (1976) 101-127.

[49] R.J. Asaro, A. Needleman, Overview no. 42 Texture development and strain hardening in rate dependent polycrystals, Acta Metallurgica 33(6) (1985) 923-953.

[50] D. Peirce, R.J. Asaro, A. Needleman, Material rate dependence and localized deformation in crystalline solids, Acta Metallurgica 31(12) (1983) 1951-1976.

[51] F. Roters, Application of crystal plasticity FEM from single crystal to bulk polycrystal, Computional Materials Science 32(3-4) (2005) 509-517.

[52] S.R. Kalidindi, C.A. Bronkhorst, L. Anand, Crystallographic texture evolution in bulk deformation processing of FCC metals, Journal of the Mechanics and Physics of Solids 40(3) (1992) 537-569.

[53] P. Shanthraj, P. Eisenlohr, M. Diehl, F. Roters, Numerically robust spectral methods for crystal plasticity simulations of heterogeneous materials, International Journal of Plasticity 66 (2015) 31-45.

[54] M. Levy, H.E. Bass, R.R. Stern, Handbook of Elastic Properties of Solids, Liquids, and Gases, Journal of the Acoustical Society of America 116(1) (2001) 15-17.

[55] Z. Claudio, Y. Yang, T.R. Bieler, R. Dierk, Orientation informed nanoindentation of $\alpha$--titanium: Indentation pileup in hexagonal metals deforming by prismatic slip, Journal of Materials Research 27(1) (2012) 356-367.

[56] S. Katani, F. Madadi, M. Atapour, S.Z. Rad, Micromechanical modelling of 
damage behaviour of Ti-6Al-4V, Materials \& Design 49 (2013) 1016-1021.

[57] X.-C. Zhang, F. Zhong, J.-B. Shao, C.-C. Zhang, N.-X. Hou, G.-J. Yuan, S.-T. Tu, Failure mechanism and mode of Ti-6Al-4V alloy under uniaxial tensile loading: Experiments and micromechanical modeling, Materials Science and Engineering: A 676 (2016) 536-545.

[58] J. Ahrens, B. Geveci, C. Law, 36 - ParaView: An End-User Tool for Large-Data Visualization, in: C.D. Hansen, C.R. Johnson (Eds.), Visualization Handbook, Butterworth-Heinemann, Burlington, 2005, pp. 717-731.

[59] U. Ayachit, The ParaView Guide: A Parallel Visualization Application, Kitware, Inc.2015.

[60] K.S. Chan, Y.D. Lee, Effects of Deformation-Induced Constraint on High-Cycle Fatigue in Ti Alloys with a Duplex Microstructure, Metallurgical and Materials Transactions A 39(7) (2008) 1665-1675.

[61] K.S. Chan, Changes in fatigue life mechanism due to soft grains and hard particles, International Journal of Fatigue 32(3) (2010) 526-534.

[62] C. Tan, Q. Sun, L. Xiao, Y. Zhao, J. Sun, Slip transmission behavior across $\alpha / \beta$ interface and strength prediction with a modified rule of mixtures in TC21 titanium alloy, Journal of Alloys and Compounds 724 (2017) 112-120.

[63] D. Qin, Y. Lu, Q. Liu, L. Zheng, L. Zhou, Transgranular shearing introduced brittlement of $\mathrm{Ti}-5 \mathrm{Al}-5 \mathrm{~V}-5 \mathrm{Mo}-3 \mathrm{Cr}$ alloy with full lamellar structure at room temperature, Materials Science and Engineering A 572(CMC2012) (2013) 19-24.

[64] C. Huang, Y. Zhao, S. Xin, W. Zhou, Q. Li, W. Zeng, Effect of microstructure on tensile properties of $\mathrm{Ti}-5 \mathrm{Al}-5 \mathrm{Mo}-5 \mathrm{~V}-3 \mathrm{Cr}-1 \mathrm{Zr}$ alloy, Journal of Alloys \& Compounds 693 (2017) 582-591.

[65] L. Lecarme, Viscoplasticity, damage, and fracture of Ti-6Al-4V, Université Catholique de Louvain, 2013.

[66] Y. Mahajan, H. Margolin, Surface cracking in $\alpha-\beta$ titanium alloys under unidirectional loading, Metallurgical Transactions A 9(3) (1978) 427-431.

[67] K. Hashimoto, H. Margolin, The role of elastic interaction stresses on the onset of slip in polycrystalline alpha brass-I. Experimental determination of operating slip systems and qualitative analysis , Acta Metallurgica 31(5) (1983) 773-785.

[68] S. Ankem, H. Margolin, A rationalization of stress-strain behavior of two-ductile phase alloys, Metallurgical Transactions A 17(12) (1986) 2209-2226. 